\title{
LA IGUALDAD EN LA EDUCACIÓN SUPERIOR: ¿MITO O REALIDAD?
}

Mónica Egea Reche

Universidad Autónoma de Madrid

Hay indicios de que no todo va tan bien como debería en las universidades de España

\section{Andreas Schleicher}

\section{El estado de la cuestión}

La discriminación en nuestra sociedad es un hecho que tiene su origen en la sociedad patriarcal y a su vez se ve reforzada por las distintas fases de socialización que van consolidando los roles sociales diferenciados por razón de género. "La familia, la escuela, los medios de comunicación de masas, etc., son los que van a contribuir de manera relevante a la formación de modelos sociales que son determinantes en la formación de la personalidad de los individuos" (Egea, 1996: 57-58). Al igual que en otras actividades de la vida cotidiana, se espera y también se exige de las mujeres y de los varones, que ejerzan el rol social que tienen asignado previamente: las chicas su papel expresivo, es decir que sean obedientes, sumisas, receptivas, cariñosas, etc., mientras que los chicos representarán su papel competitivo, realizando actividades mecánicas, de fuerza e incluso de agresividad. La reproducción de las consabidas dicotomías sobre lo que se considera masculino y femenino, lo "cultural" y lo "natural". 
Ellos juegan a algún deporte, generalmente al fútbol y ellas se cuentan sus cosas, estableciéndose el conocido orden: los niños aprenden sobre competencia, las niñas aprenden sobre relaciones. Los mecanismos establecidos de reproducción social, perpetúan una ordenación jerárquica de los géneros masculino y femenino y de lo que se considera importante o subsidiario.

La vida discrimina sistemáticamente, y a veces de forma sutil, a las mujeres. Es en este proceso de socialización y fundamentalmente a través de la educación, cuando las edades y las posibilidades de cambio son más propicias, donde hay que atajar el problema. Como dice Mirian E. David, cuando presenta la obra de la profesora universitaria y educadora Sandra Acker: "Al final, esto puede suponer tanto una debilidad como un punto de apoyo para intentar convencer (también) a las instituciones educativas para que tomen en serio la problemática del género" (Acker, 1995: 19).

\section{El espacio europeo}

En el marco de acción que la Comisión de las Comunidades Europeas establece para eliminar las desigualdades y fomentar la plena participación de hombres y mujeres, se han puesto en marcha sucesivos planes que establecen como principal objetivo: “eliminar las desigualdades y fomentar la igualdad entre hombres y mujeres", centrándose a continuación en los cinco objetivos que constituyen el marco de referencia de las políticas comunitarias:

- la igualdad en la vida económica

- la igualdad de representación y participación en la toma de decisiones

- la igualdad en la vida social

- la igualdad en la vida cívica, y

- $\quad$ la modificación de roles establecidos en función del sexo

El planteamiento político de la Unión se apoya en una idea sustancial: "La 
La igualdad en la educación superior: ¿mito o realidad?

democracia es uno de los valores fundamentales de la Unión Europea, de sus Estados miembros, de los países del EEE y de los países candidatos a la adhesión”. Es así que requiere para su ejecución la plena participación de todos los ciudadanos, hombres y mujeres por igual, y la representación igualitaria de ambos sexos en los distintos ámbitos de la vida social, cultural y civil.

En el marco de Naciones Unidas también se contempla la necesidad de que desaparezcan las desigualdades en la comunidad global dentro de un "buen gobierno democrático"".

Los acuerdos de Pekín de 1995 reiteran la importancia de luchar contra la discriminación por todo tipo de motivos y se insiste en la necesidad de elaborar indicadores e información estadística donde aparezcan datos segregados por sexos, en la línea de los informes presentados por el Parlamento y por el Comité Económico y Social europeo. A veces la información no segregada esconde situaciones discriminatorias haciendo invisible la situación de las mujeres.

\section{El caso de la educación superior}

El tema que nos ocupa pone de relieve cómo se ha producido el acceso democrático de chicos y chicas a cualquier nivel de estudios y es particularmente notorio el incremento de mujeres matriculadas en la universidad.

Queda ya muy lejos la necesidad de disfrazarse de hombre para poder entrar en un aula universitaria, o el abandono de los estudios para formar una familia, hechos que nos permitirían sostener que se ha superado la discriminación histórica que relegaba mayoritariamente a las mujeres a su preparación exclusiva para ser buenas esposas, madres y cuidadoras del hogar.

\footnotetext{
${ }^{1}$ Naciones Unidas. Convención para la Eliminación de todas las formas de discriminación contra las mujeres y su significado. Ratificado por la Conferencia de Derechos Humanos celebrada en Viena en el año 1993.
} 
Si tenemos en cuenta los aspectos cuantitativos, las mujeres no sólo acceden a los estudios superiores sino que incluso son mayoría las alumnas que se encuentran en los centros universitarios frente a un número menor de hombres que estudian. En este sentido, en la Universidad Autónoma de Madrid $^{2}$ en los tres últimos años, las alumnas cuentan con una mayor representación, también por el número de titulados, así como por los mejores expedientes académicos. Sin embargo persisten pautas tradicionales en relación a las especialidades que siguen eligiendo las chicas, como Maestra en Educación Infantil, Filología Clásica, Historia y Teoría del Arte, Estudios Árabes Islámicos, etc. Como podemos apreciar a continuación:

Titulados/as ${ }^{3}$ :

Curso 1999-2000: hombres 35\% mujeres 65\%

Curso 2000-2001: hombres 37\% mujeres 63\%

Curso 2001-2002: hombres 38\% mujeres 62\%

Se puede comprobar que hay más títulos expedidos a mujeres que a hombres, con un ligero descenso para éstas según se ha pasado de 1999 al 2002.

En las diplomaturas aparecen proporcionalmente más mujeres que en las licenciaturas, superando en ambas el porcentaje de chicas sobre chicos:

$\begin{array}{ll}\text { Curso 1999-2000 } & \text { Diplomaturas - mujeres 81,3\% } \\ & \text { Licenciaturas - mujeres 62,3\% } \\ \text { Curso 2000-2001 } & \text { Diplomaturas - mujeres 81,2\% } \\ & \text { Licenciaturas - mujeres 63,4\% } \\ \text { Curso 2001-2002 } & \text { Diplomaturas - mujeres 83,3\% } \\ & \text { Licenciaturas - mujeres 62,1\% }\end{array}$

${ }^{2}$ Participación y toma de decisiones en la Universidad Autónoma de Madrid. Investigación enmarcada en los objetivos del IV Plan de Igualdad de Oportunidades de Hombres y Mujeres de la Comunidad de Madrid (2002-2005) Dirección y realización: Mónica Egea Reche. IUEM. Univ. Autónoma de Madrid. 
La igualdad en la educación superior: ¿mito o realidad?

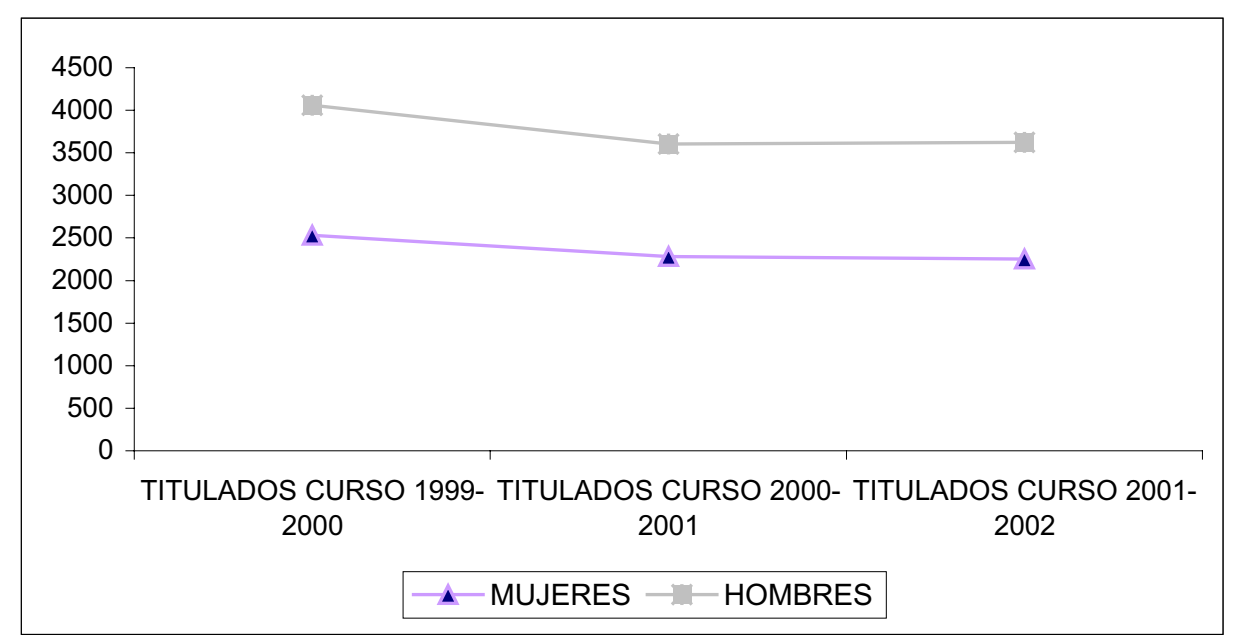

La Diplomatura de Maestro en Educación Infantil es la más feminizada correspondiendo a los citados cursos, el $95,7 \%$, el $95,9 \%$ y el $94 \%$ respectivamente. Y la más baja representación femenina la tiene la Diplomatura de Maestro en Educación Física con el 43,6\%, el 41,7\% y el 42\% respecto a los mismos cursos.

Para el curso 1999-2000, la licenciatura más feminizada fue Filología Clásica con un $100 \%$ de mujeres y la que menos Ingeniería Informática con un $15,2 \%$. En el curso 2000-2001, también con el 100\% de chicas destacó Filología Francesa y repite Ingeniería Informática con un 14,5\% de representación femenina. El curso 2001-2002 presenta la licenciatura de Filología Árabe, con el 86,7\% como la más feminizada y en Ingeniería Informática sube hasta un 21,8\% la proporción de chicas. Aunque algo está cambiando, las mujeres siguen decantándose mayoritariamente por la opción de ciencias sociales, mientras que los varones eligen en mayor medida la rama científico-técnica.

Por lo que respecta a los últimos datos conocidos sobre los estudiantes que se

${ }^{3}$ La UAM en cifras, 2003. 
presentaron a las pruebas de selectividad a nivel nacional en el $2005^{4}$, el $58,1 \%$ fueron mujeres, de las cuales aprobaron el 82,2\%. Del 41,9\% de hombres que se presentaron, superaron la prueba el $81 \%$, apreciándose un ligero mejor resultado para las chicas.

Con estos datos podríamos inducir que si el estamento del alumnado tiene una mayor representación de mujeres, también se podría plasmar esa misma situación en el acceso al PDI (Personal Docente e Investigador), que sin embargo representa en la UAM el $65 \%$ de hombres y el $35 \%$ de mujeres. De los cuales son funcionarios el $70 \%$ de hombres y el 30\% de mujeres, acercándose más en lo que se refiere al PDI contratado con un $55 \%$ de varones y el $45 \%$ de mujeres. Los hombres son más numerosos en todas y cada una de las categorías funcionariales, especialmente en el acceso a cátedras. En la UAM para el curso 2001-02, hay sólo un 6\% de mujeres catedráticas, el $47 \%$ de profesoras titulares, el 38\% con contrato de asociado, el 9\% ayudantes y el resto poco significativo son visitantes y eméritas. A nivel nacional, las catedráticas de universidad son el $12,75 \%$, las titulares el 36,45\% y las asociadas el 34,78\% (INE. Estadística de la Enseñanza Superior en España).

Respecto al personal de administración y servicios la presencia femenina es importante en todos los centros de la UAM (el 36\% son varones y el 64\% mujeres).

La diferencia de género se observa en todos los ámbitos analizados ${ }^{5}$. La presencia masculina es sensiblemente mayor en los órganos unipersonales de gobierno de la universidad: el puesto de Rector es ocupado por un hombre, al igual que el de Gerente, y al frente de la Secretaría general está una mujer. La representación de quienes encabezan los vicerrectorados se acerca a la paridad con seis hombres y cinco mujeres. Y otros órganos de gobierno y la mayor parte de las comisiones están presididas por varones.

Los dos órganos más discriminatorios son el Consejo Social y el Comité de Empresa, con una representación femenina del 19\% y el 18\% respectivamente. En la

${ }^{4}$ EL PAÍS, 27 de enero de 2006, p. 29 
La igualdad en la educación superior: ¿mito o realidad?

Junta de Personal de Administración y Servicios la presencia de hombres supera a la de mujeres, cuando existe un 64\% más de personal femenino de esta categoría.

Todos los centros tienen más personal docente e investigador masculino, salvo en Formación de Profesorado, que como todo el mundo sabe, la tarea de Maestra siempre ha sido muy femenina.

\section{Probabilidades de mejora}

$\mathrm{Si}$, como ya es notorio, las mujeres pueden y acceden de hecho a la universidad en igualdad de condiciones con sus compañeros varones y salen con una preparación que las habilita para el ejercicio profesional, es en la incorporación al mundo laboral cuando se mantiene el modelo tradicional.

Habría que preguntarse si los contenidos de la formación académica no llegan a cuestionarse la transmisión sexista de la ciencia, si siguen primando los valores tradicionales que ensalzan las tareas de las mujeres ligadas a su propia biología, si nos interesa en definitiva a todos tener una sociedad más justa y democrática.

El sistema educativo, en todos sus niveles, tiene que actuar de manera inequívoca para construir nuevas formas de pensamiento, transformando a su vez nuevos modos de actuar y que todos podamos sentirnos tratados con equidad.

Es lo que preocupa también al máximo responsable del Informe Pisa, Andreas Schleicher, que ha investigado los aspectos cualitativos en los niveles de educación básica y que parece interesado en la necesidad de analizar también la educación superior. Hace especial referencia a nuestro país en un reciente artículo en donde afirma:

Hoy, una de cada cuatro personas con edad comprendida entre 25 y 24 años obtiene un título universitario en España (...). España (...) deberá lograr que su

\footnotetext{
${ }^{5}$ Participación y toma de decisiones en la Universidad Autónoma de Madrid...
} 
éxito en expandir la cantidad de universitarios vaya unido con la introducción de estándares de calidad competitivos internacionalmente. ${ }^{6}$

De lo cual podemos deducir que una cosa es la cantidad y otra la calidad. Con la investigación realizada en la Universidad Autónoma de Madrid ${ }^{7}$ queremos contribuir a la concienciación sobre la situación real en que se encuentra nuestra universidad. Vemos como la igualdad de oportunidades sólo se cumple en el acceso a los estudios superiores. Tenemos que visualizar el techo de cristal que todavía existe para acceder por igual a todos los puestos de gestión, docencia e investigación. Debemos de ser conscientes de que existe un déficit democrático porque las mujeres no están suficientemente representadas en todos los estamentos institucionales.

\section{A modo de conclusión}

Las mujeres queremos participar y colaborar en las transformaciones de la sociedad, queremos ser sujetos activos de un nuevo modelo donde no aparezca la división sexual de tareas y queremos que las relaciones sociales se lleven a cabo entre iguales.

\footnotetext{
${ }^{6}$ SCHLEICHER, www.madri+d.org. 16 de enero del 2006.

${ }^{7}$ Participación y toma de decisiones en la Universidad Autónoma de Madrid...
} 
La igualdad en la educación superior: ¿mito o realidad?

\section{BIBLIOGRAFÍA}

ACKER, S. (1995): Género y educación. Reflexiones sociológicas sobre mujeres, enseñanza y feminismo. Madrid: Narcea.

EGEA Reche, Mónica (1996): "Los roles de género, una construcción social. Reflexiones para la Educación Secundaria". Monográfico "Educación para la Igualdad", Tarbiya no 14. Págs. 57-63. Revista de investigación e innovación educativa. ICE. Universidad Autónoma de Madrid.

EL PAÍS, 27 de enero de 2006: "Aprobados en Selectividad 2005".

Instituto de La Mujer (2002): Guía de Desarrollo de Acciones Positivas. Material didáctico del Programa Óptima de Igualdad de Oportunidades Ministerio de Trabajo y Asuntos Sociales. Madrid.

INE. Estadística de la Enseñanza Superior en España.

IV Plan de Igualdad de Oportunidades de Mujeres y Hombres de la Comunidad de Madrid (2002-2005).

NuÑo GómeZ, L. (1999): Mujeres: de lo privado a lo público. Madrid: Tecnos.

PAdilla, M. (2003): “En 30 años el n ${ }^{\circ}$ de profesoras del CSIC sólo ha aumentado del 8\% al 15\%”. En www.madri+d.org. 17 de noviembre del 2003.

SCHLEICHER, Andreas (2006): "El problema de la universidad", en www.madri+d.org. 16 de enero del 2006.

UAM en cifras. Curso académico 2000-2001 y 2001-2002.

VALle, Teresa del (2002): Modelos emergentes en los sistemas y las relaciones de género. Madrid: Narcea. 
